\title{
Upper extremity joint stresses during walker- assisted ambulation in post-surgical patients
}

\author{
Estresse articular no membro superior durante marcha assistida por andador \\ em pacientes pós-cirúrgicos
}

Kevin J. McQuade', Margaret Finley², Anamaria S. Oliveira ${ }^{3}$

\begin{abstract}
Background: A walker is a common device prescribed for ambulatory assistance for individuals with balance difficulties or to reduce lower extremity demands following injury or surgery. The long-term use of a walker imposes significant demands on the patient's upper extremities that may lead to increased risk for development of secondary conditions such as wrist, elbow or shoulder pain. Objective: To describe the joint kinematics, forces and moments of the wrist, elbow and shoulder in a sample of twenty patients that were using a walker as a result of total joint surgery of the hips and knees. Methods: Three-dimensional upper extremity kinematics were recorded using a motion capture system synchronized with forces and torques transmitted through a walker instrumented with force transducers in the handles. Results: Compressive forces were found to be nearly $20 \%$ of the body weight at each of the upper extremity joints, both surgical and non-surgical sides, being the greatest force at the wrist and decreasing proximally. Compression forces were greater in the non-surgical side limb at the wrist and at the elbow. Conclusion: Our findings indicated that loads on upper extremity joints associated with the use of a walker for assisted ambulation are high and further studies are needed to address the cause-effect relationship between the actual joint loading and the development of secondary musculoskeletal upper extremity complaints in more frail patients.

Keywords: upper extremity; biomechanics; gait; shoulder; equipment; supplies.

\section{Resumo}

Contextualização: Um andador é um dispositivo frequentemente prescrito para auxiliar a marcha de indivíduos com dificuldades de equilíbrio ou para reduzir demandas à extremidade inferior após cirurgia ou lesão. O uso prolongado de um andador impõe significante demanda para a extremidade superior do paciente, o que pode levar a um risco aumentado de desenvolver condições secundárias, como dor no punho, cotovelo e ombro. Objetivo: Descrever a cinemática articular, forças e momentos do punho, cotovelo e ombro de uma amostra de 20 pacientes que faziam uso de um andador após cirurgia de substituição articular do joelho ou quadril. Métodos: A cinemática tridimensional foi registrada usando um sistema de captura de movimento sincronizado com o registro de transdutores de força, que mediam a força transmitida através do andador. Resultados: Este estudo revelou forças de até $20 \%$ do peso corporal nos transdutores, com forças compressivas maiores do lado do membro inferior não operado, no punho e no cotovelo. Conclusão: Os achados indicam que demandas no membro superior associadas ao uso de andador como dispositivo auxiliar da marcha são grandes, e mais estudos são necessários para averiguar relações de causa-efeito entre as reais sobrecargas articulares e o desenvolvimento de queixas musculoesqueléticas no membro de pacientes em condições de debilidade.
\end{abstract}

Palavras-chave: extremidade superior; biomecânica; marcha; ombro; equipamentos; provisões.

Received: 15/02/2011 - Revised: 21/02/2011 - Accepted: 28/03/2011

${ }^{1}$ Department of Rehabilitation Medicine, University of Washington (UW), Seattle, WA, USA

${ }^{2}$ Krannert School of Physical Therapy, University of Indianapolis (UIndy), Indianapolis, In, USA

${ }^{3}$ Department of Biomechanics, Medicine and Rehabilitation of Locomotor Apparatus, Universidade de São Paulo (USP), Ribeirão Preto, SP, Brazil

Correspondence to: Anamaria Siriani de Oliveira, Prédio Central, Curso de Fisioterapia, Rodovia Bandeirantes, 3900 Monte Alegre, CEP 14049-900, Ribeirão Preto, SP, Brasil,

e-mail: siriani@fmrp.usp.br 


\section{Introduction $: \therefore$.}

Common diagnoses associated with the prescription of assistive devices such as walkers include hip fracture, lower limb amputation, generalized deconditioning, stroke, a variety of balance disorders and post operative hip and knee joint replacement ${ }^{1}$. The highest demand for short-term use of assistive devices are associated with rehabilitation of lower extremity surgeries, when patients are just beginning to be allowed of bearing their weight through the lower extremities ${ }^{2-4}$.

Upper limb extremity conditions, such as carpal tunnel syndrome $^{5,6}$, median neuropathy ${ }^{7,8}$, stress fractures ${ }^{9}$ and upper limb risk of pain ${ }^{10}$ were previously associated to chronic use of ambulatory devices. However, little is known about the stresses placed on the upper extremities during ambulation with assistive devices.

There has been some evaluation of shoulder torques during crutch ambulation indicating that high shoulder extensor moments are required ${ }^{11}$. When crutches were used incorrectly, 34\% bodyweight was carried by the underarm. Goh, Toh and Bose ${ }^{12}$ reported that this overload could cause undue pressure over the neurovascular structures at the axillary region. However, there are no studies on the use of walkers. Bachschmidt, Harris and Simoneau ${ }^{13}$. demonstrated high peak magnitudes of internal joint moments in upper extremities of young healthy subjects using walkers to perform three-point ambulation gait with non-weight bearing and partial weight bearing at $10 \%$ and $50 \%$.

In order to understand the acute demands on the upper extremities of walker's users, the objective of this study was to describe the joint forces and moments of the wrist, elbow and shoulder in a sample of patients that are using a walker as a result of total joint surgery of the hips and knees.

\section{Methods $: \because$.}

Following reading and signing informed consent and Health Insurance Portability and Accountability Act (HIPAA) authorization documents approved by the University of Mariland Internal Review Board, Baltimore, EUA [protocol \#0699118], individuals from nearest area, were enrolled in the study after hip or knee joint replacement surgery. Twenty patients, being 9 females and 11 males were included in this study. Their average age was 67 years (range, 49-84 years), average height of $1.7 \mathrm{~m}$ (range, 1.5-1.9 m), average weight of $90 \mathrm{~kg}$ (range, 56-110 kg) and average post-operative day at data collecting procedure were 9 (range, 34-2) days. Eight of those patients had undergone total hip replacement and 12 had total knee replacement. All subjects were in good health, demonstrated functional upper extremity range of motion, normal upper extremity function ${ }^{14}(4+/ 5$ to $5 / 5)$, and intact upper extremity sensation as measured by one physical therapist. All of them had their postoperative pain level relieved and controlled by non-steroidal anti-inflammatory drugs (NSAIDs).

Subjects were setup for three-dimensional gait analysis using three active infra-red cameras (Optotrack ${ }^{\circledR}$, Northern Digital Inc., Waterloo, Ontario). Three-dimensional kinematics of both upper extremities was collected at $100 \mathrm{~Hz}$. Three noncollinear infrared light emitting diodes were attached to a rigid platform that was then attached to each limb segment using Velcro straps. Additional strapping of each limb was used to fix markers and cables. Local coordinate reference frames for the trunk, upper arm, forearm and hand were defined by digitization of anatomical landmarks using a digitizing stylus and specialized software (MotionMonitor ${ }^{\mathrm{TM}}$ Innovative Sports Training, Chicago, IL). Positive axes were defined by anterior (x), lateral to the left (y) and superior (z). Three-dimensional Euler angles were calculated for rotations about the segment axes. Centroid calculation of digitized joint landmarks defined the joint center of the wrist (midpoint of radial and ulnar styloid process) and elbow (midpoint of medial and lateral epicondyle). The shoulder joint center was defined by the centroid of the anterior and posterior acromion and a point $5 \mathrm{~cm}$ inferior from the line connecting the anterior and posterior edges of the acromion.

Two commercial strain gauge transducers designed for the measurement of forces and moments transmitted through standard four-legs walkers (AMTI, Watertown, MA, USA) were integrated into both walker's handgrips. The instrumentation of the walker added $1.2 \mathrm{~kg}$ to the overall weight of the walker. Signals were amplified with MSA-6 strain gauge amplifier(AMTI, Watertown, MA, USA) and synchronized with the kinematics. Force transducer data was collected at $200 \mathrm{~Hz}$ and low pass filtered using a $20 \mathrm{~Hz}$ recursive $4^{\text {th }}$ order Butterworth filter. Net joint forces, and moments and were calculated using standard inverse dynamics methods using segment anthropometrics, linear and angular kinematics, and the walker transducer three-dimensional forces.

The walker transducers created an external force vector analogous to the ground reaction force vector of a force platform. The center of mass of the hand was used as the point of application for the walker transducer forces. Joint compressive forces were those forces acting in the direction of the local segment long axis; anterior shear was represented by joint forces along the anterior/posterior axes of the segment. Joint moments were defined for Flexion/extension, Abduction/ Adduction and Internal/external rotation of the shoulder, 
Flexion/extension of the elbow, and for wrist flexion/extension, and radial/ulnar deviation.

Allvolunteers have had previouslyinstructed by one physical therapist in the first post-operative day about how to use one walker to ambulate. All were independent in using a standard walker for mobility assistance following the joint replacement surgery. In the Human Motion Laboratory the instrumented walker's handgrip height was adjusted to the height of each subject. The instrumented walker was placed in front of the patient so the walker's back legs were aligned to volunteer's mid-foot. The handgrip was adjusted to the level of the greater trochanter, ulnar styloid process, or volar wrist crease while the elbow was positioned at 20-25 degrees of flexion when the volunteer rested his/her hand on the handgrip ${ }^{15}$.

They were instructed to perform the three-one-point gait pattern (Figure 1) with weight bearing as tolerated (WBAT). During WBAT patients were instructed to determine the amount of weight bearing that will occur on the involved extremity, ranging from minimal to full, in which they were free of pain ${ }^{15}$. Following subject set up for kinematic data collection, subjects were instructed to ambulate ten feet at a self-selected pace. They repeated this three times with rest between trials as needed. We collected three complete strides per trial and averaged the nine trials.

A complete walker step cycle was defined as beginning of positive vertical hand transducer force greater than $10 \mathrm{~N}$, loading in the walker handles through pick up of the walker to next initial loading (contact-swing-contact). This represented $0-100 \%$ of the walker step cycle. The left and right strides were normalized with regards to the step cycle separately to consider asymmetrical loading.

\section{Statistical analysis}

Forces and moments were normalized to the subject body weight (BW). Peak values were calculated for sagittal plane moments in the three studied joints. Compressive and anterior shear peak forces were also calculated. All these mean variables were compared between surgical and nonsurgical sides. Paired t-tests determined if differences existed between the corresponding upper extremity of the surgical lower limb and the non-surgical sides. Level of significance was set at $5 \%$.

The ensemble average of all subject's data of normalized hand force and joints angles were plotted against the percentage of step up cycles, resulting in representative kinetic and kinematic patterns of wrist, elbow, and shoulder joints. Spearman Rank Correlation was used to determine if a relationship existed between the total percentage of body weight born through the walker and the number of postoperative days which had elapsed before testing. All statistics were performed using the statistical package SPSS (version 11.5) for Windows.

\section{Results $\because \because$}

On average, the subjects weighted $46.1 \%( \pm 13.9 \%)$ of their body weight (BW) on their upper extremities during ambulation, with $25.7( \pm 7.0 \%)$ of BW and $20.4( \pm 8.5 \%)$ of BW being distributed toward the non-surgical and surgical side, respectively. There was no significant correlation between the number of days post-surgery with the variables total loading $(\mathrm{r}=-0.19)$, non surgical limb $(\mathrm{r}=-0.53)$ and surgical limb $(\mathrm{r}=-0.42)$.

No statistically significant difference was found between the surgical and non-surgical side on the upper extremity joint kinematics. The wrist was found to be near neutral at contact and due to the progression of the forearm over the hand, the radial deviation angle increased until near peak hand force, then ulnar deviation was seen throughout the remainder of the cycle. The elbows were in flexion at initial contact, extended until peak hand loading, following which the elbows moved into flexion until the end of the cycle. Shoulder angles began in slight flexion and as the body progressed over the walker the shoulders moved into extension until after the swing phase started. Since there was no difference between the sides, the two sides were averaged to present the combined generalized profile of the ensemble averaged upper extremity kinematics of all 20 subjects in Figure 2.

Peak forces at the hand transducer were greater in the non-surgical side (Figure 3) however, no difference was found
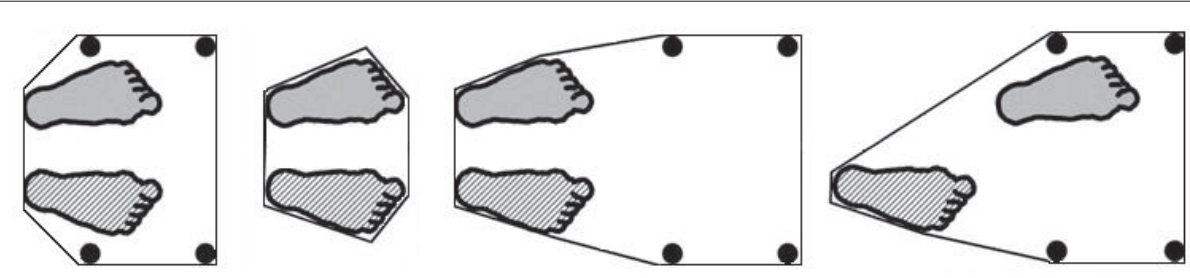

affected foot

unaffected foot

$\square$ base of support

- walker

Figure 1. The three-one-point gait pattern showing sequence of movements for affected and unaffected feet and walker. 


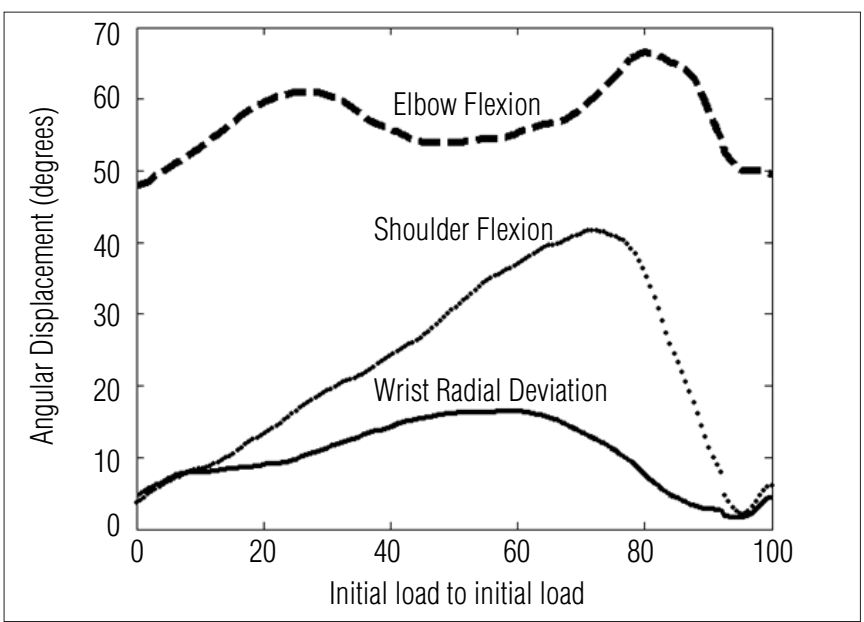

Figure 2. Combined ensemble average of upper extremity primary angular displacements for the wrist(radial/ulnar deviation) Elbow (flexion/extension) and shoulder (flexion/extension) during walker ambulation ( $\mathrm{n}=20)$.

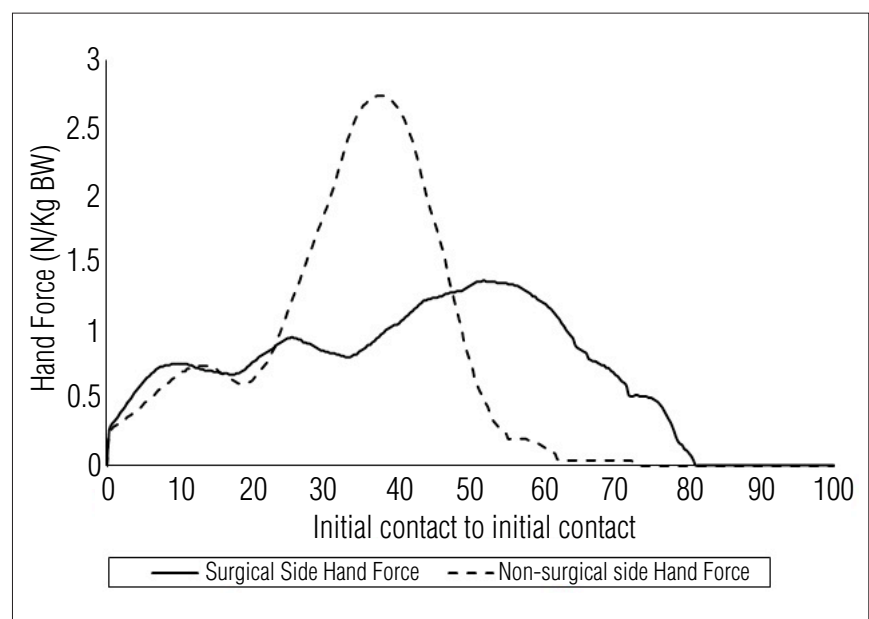

Figure 3. Ensemble average of hand transducer forces normalized for body weight. Surgical versus non-surgical side $(\mathrm{n}=20)$.

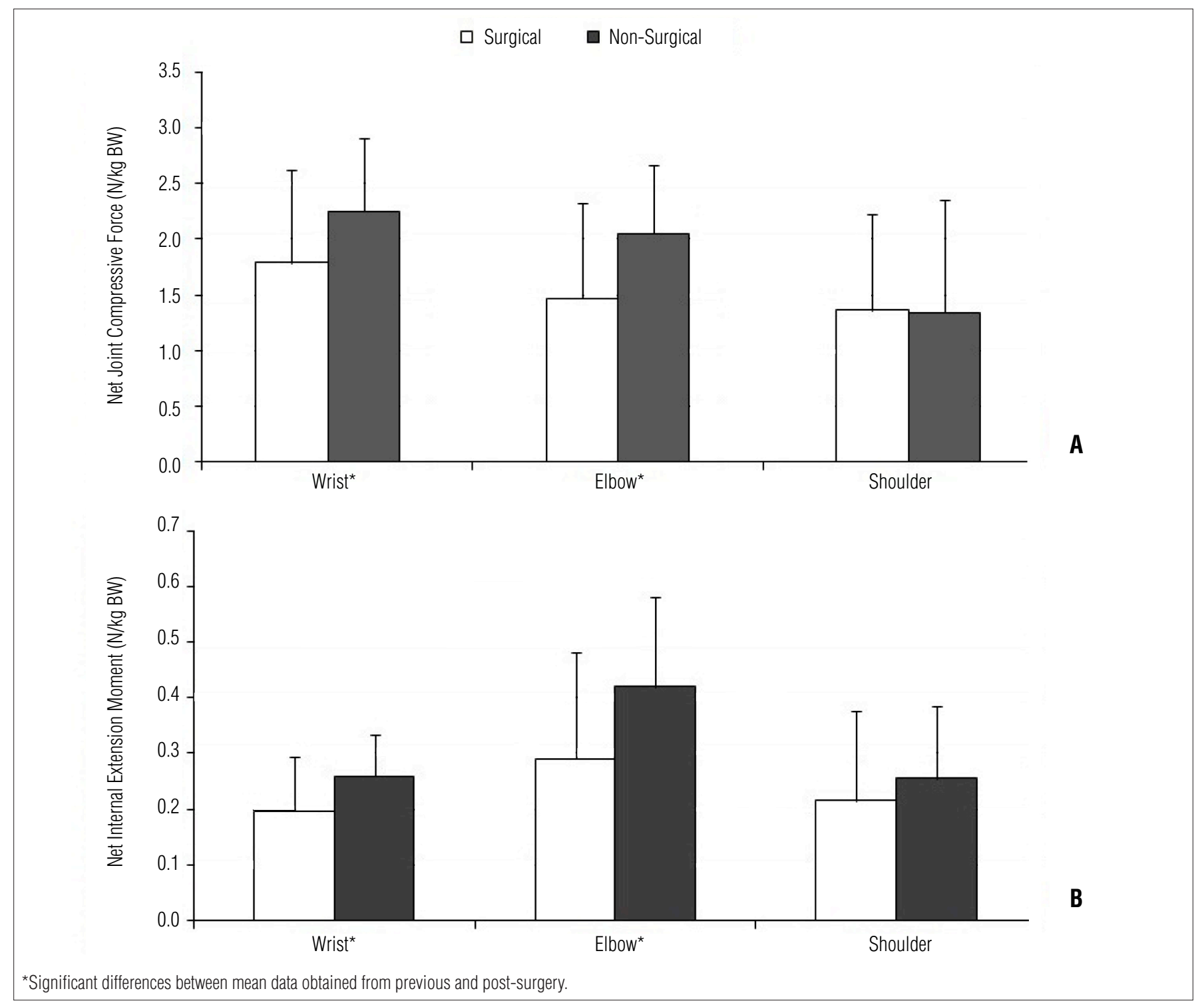

Figure 4. (A) Net joint compressive (vertical) forces on the upper extremity joints normalized to body weight. Surgical versus non-surgical side $(n=20)$. (B) Net internal principle joint moments of the upper extremity normalized to body weight. Surgical versus non-surgical side during walker ambulation ( $\mathrm{n}=20)$. Wrist ulnar deviation, Elbow extensor moment, and Shoulder extensor moments. 
in the total area during contact time (impulse) for the nonsurgical limb (surgical $=241.2 \pm 143.0 \mathrm{~N} / \mathrm{kg} \mathrm{BW}$, non-surgical $=273.2 \pm 108.8 \mathrm{~N} / \mathrm{kg} \mathrm{BW}$ ). The compressive forces in the wrist $(p \leq 0.01)$ and elbow $(p \leq 0.01)$ were found to be greater in the non surgical side upper extremity (Figure 4A). Peak anterior shear forces were also larger $(\mathrm{p}=0.02)$ for the non-surgical side wrist. No difference was seen at the level of the shoulder joint. Larger sagittal plane moments were found in wrist (ulnar deviation, $\mathrm{p}=0.01$ ) and elbow (extension, $\mathrm{p} \leq 0.01$ ) for the non-surgical limb as compared with the surgical side upper extremity (Figure 4B).

\section{Discussion $: \because$.}

Compressive forces were found to be nearly $20 \% \mathrm{BW}$ at each of the upper extremity joints, both surgical and non-surgical lower limb sides, being greatest at the wrist and decreasing proximally. Because the upper extremity joints are functionally and structurally designed for mobility rather than as weight bearing joints, the use of these types of mobility devices places increased demands on the user's upper extremities ${ }^{16,17}$. Individuals who chronically use their upper extremities for weight bearing relief maneuvers demonstrate a high prevalence of carpal tunnel syndrome and wrist pain ${ }^{5-8,18}$. While both wrist and elbow problems are reported, shoulder pain is the most common upper extremity orthopedic co-morbid condition in long-term users of these types of devices ${ }^{19}$.

The upper extremity joint kinematic patterns reported in this study are similar to those reported in previous research ${ }^{13}$. The upper extremity patterns resemble those during normal gait with extension of the proximal and distal joint and a flexion-extension combination in the middle joint indicating a synchrony of upper and lower extremities motion patterns during the ambulation using a non-wheeled walker.

In agreement with a previous report ${ }^{13}$ the highest internal joint moment was found at the elbow. When averaged across both extremities, the sagittal plane joint moment for the elbow $(0.36 \pm 0.2 \mathrm{Nm} / \mathrm{kg})$ was similar to comparative study values for $50 \%$ body weight loading ${ }^{10}$. However, the wrist $(0.23 \pm 0.1 \mathrm{Nm} / \mathrm{kg})$ and shoulder $(0.23 \pm 0.1 \mathrm{Nm} / \mathrm{kg})$ moments were greater in the current research than those reported by Bachschmidt, Harris and Simoneau ${ }^{13}$. On the other hand, Pardo ${ }^{16}$ found larger ulnar deviation moments $(0.5 \mathrm{Nm} / \mathrm{kg})$ when studying subjects with lower limb amputation using a walker. This could be attributed to the use of different axes definitions, normalization procedures, and/or the use post-surgical patients as subjects, rather than young, uninjured adults as participants.

An interesting finding was the asymmetry of the loading magnitude in the correspondent non-surgical upper-limb side compared with the upper extremity loading in the surgical side. Subjects consistently placed higher upper limb peak loads on the side opposite of their surgical limb, resulting in higher compressive forces at the wrist and the elbow. This was true even though subjects were instructed by physical therapists and self-reported they were using the walker symmetrically. Although the absolute peak loads were greater, the impulse loading was not found to be different, indicating that forces on the surgical side upper extremity were applied over a longer period of time. Potential for wear increases with both high peak loads as well as from repetitive submaximal loads ${ }^{20-22}$. Debate remains as to which factor: rate, magnitude or frequency of loading is the most detrimental to the joint tissue ${ }^{23-25}$. Since walker ambulation creates repetitive, asymmetrical loads of both extremities, as well as greater peak loads on the nonsurgical side, we speculate that the potential for development of upper extremity pathology would be greater on this limb. However, it is unknown which biomechanical factor lead to the development of secondary upper extremity pathologies in individuals who use upper extremity weight bearing devices, such as wheelchairs, canes and walkers.

A standard biomechanical model that could bring more understanding of upper limbs motion and forces has being investigated ${ }^{26,27}$. A properly biomechanical model may capture a single joint; or a group of joints such as the shoulder, elbow and wrist; or a combination of joints and an ambulatory aid, which serves as the extension of the upper $\operatorname{arm}^{27}$. Unfortunately, due to the complex nature of upper body movements, just recently a three-dimensional biomechanical model for a thorough investigating of loads impose to upper limbs as resulting of crutch-assisted gait is available ${ }^{27}$.

Although the current subjects were post-surgical patients, they were in good health with normal upper extremity strength and function and utilized the walker for a reduction of lower extremity weight-bearing of less than $50 \%$ BW. It has been shown that upper extremity strength and joint pathology may be important limiting factors for walker users ${ }^{2,16,28}$. Of concern is that many walker users are frail, elderly individuals and may not have the upper extremity strength to meet the higher demands of walker use during rehabilitation of a hip fracture, for example. This suggests that upper extremity strength may also need to be addressed and incorporated into the rehabilitation program.

\section{Conclusion $: \because$.}

The results of this study indicate that demands on upper extremity joints associated with the use of a walker for assisted ambulation can reach as much $20 \%$ body weight. The torques on the joints at the elbow tends to be the greatest suggesting 
high muscular demands of the elbow extensors and shoulder extensors. From our analysis of the upper extremity weight bearing loads, it can be determined that on average, the subjects were only loading the surgical limb with $54 \%$ body weight. Whether this amount of body weight can be considered to be sufficient to facilitate optimal healing or is an excessive load is unknown at this time. Further studies using a prospective design are needed to address the cause-effect relationship between the actual joint loading, rate of loading and the development of secondary musculoskeletal upper extremity complaints in frailer assistive device users.

\section{References $: \because$.}

1. Mincer $A B$. Assistive devices for the adult patient with orthopaedic dysfunction. Why physical therapists choose what they do. Orthop Nurs. 2007;26(4):226-31.

2. Joyce BM, Kirby RL. Canes, crutches and walkers. Am Fam Physician. 1991;43(2):535-42.

3. Russell JN, Hendershot GE, LeClere F, Howie LJ, Adler M. Trends and differential use of assistive technology devices: United States, 1994. Adv Data. 1997;(292):1-9.

4. Youdas JW, Kotajarvi BJ, Padgett DJ, Kaufman KR. Partial weight-bearing gait using conventional assistive devices. Arch Phys Med Rehabil. 2005;86(3):394-8.

5. Waring WP 3rd, Werner RA. Clinical management of carpal tunnel syndrome in patients with long-term sequelae of poliomyelitis. J Hand Surg Am. 1989;14(5):865-9.

6. Stevens JC, Beard CM, O'Fallon WM, Kurland LT. Conditions associated with carpal tunnel syndrome. Mayo Clin Proc. 1992;67(6):541-8.

7. Werner R, Waring W, Davidoff G. Risk factors for median mononeuropathy of the wrist in postpoliomyelitis patients. Arch Phys Med Rehabil. 1989;70(6):464-7.

8. Tsai HC, Hung TH, Chen CC, Lieu FK, Cho H, Tung TH, et al. Prevalence and risk factors for upper extremity entrapment neuropathies in polio survivors. J Rehabil Med. 2009;41(1):26-31.

9. Moyers PA. The guide to occupational therapy practice. American Occupational Therapy Association. Am J Occup Ther. 1999:53(3):247-322.

10. Koh ES, Williams AJ, Povlsen B. Upper-limb pain in long-term poliomyelitis. QJM. 2002;95(6):389-95.

11. Opila KA, Nicol AC, Paul JP. Upper limb loadings of gait with crutches. J Biomech Eng. 1987;109(4):285-90

12. Goh JC, Toh SL, Bose K. Biomechanical study on axillary crutches during single-leg swingthrough gait. Prosthet Orthot Int. 1986;10(2):89-95.

13. Bachschmidt RA, Harris GF, Simoneau GG. Walker-assisted gait in rehabilitation: a study of biomechanics and instrumentation. IEEE Trans Neural Syst Rehabil Eng. 2001;9(1):96-105.

14. Kendall FP, McCreary EK, Provance PG, Rodgers M, Romani W. Muscles: Testing and. Function with Posture and Pain. $5^{\text {th }}$ ed. New York: Williams and Wilkins; 2005

15. Pierson FM, Fairchild SL. Principles \& Techniques of Patient Care. $4^{\text {th }}$ ed. Philadelphia, PA: W B Saunders; 2008.
16. Pardo RD, Deathe $A B$, Winter DA. Walker user risk index. A method for quantifying stability in walker users. Am J Phys Med Rehabil. 1993;72(5):301-5.

17. Pentland WE, Twomey LT. The weight-bearing upper extremity in women with long term paraplegia. Paraplegia. 1991;29(8):521-30.

18. Gellman H, Sie I, Waters RL. Late complications of the weight-bearing upper extremity in the paraplegic patient. Clin Orthop Relat Res. 1988;(233):132-5.

19. Rice DP, LaPlante MP. Medical expenditures for disability and disabling comorbidity. Am J Public Health. 1992;82(5):739-41.

20. Lories RJ. Joint homeostasis, restoration, and remodeling in osteoarthritis. Best Pract Res Clin Rheumatol. 2008;22(2):209-20

21. Bingham JT, Papannagari R, Van de Velde SK, Gross C, Gill TJ, Felson DT, et al. In vivo cartilage contact deformation in the healthy human tibiofemoral joint. Rheumatology (Oxford) 2008;47(11):1622-7.

22. Hosseini A, Van de Velde SK, Kozanek M, Gill TJ, Grodzinsky AJ, Rubash HE, et al. In-vivo timedependent articular cartilage contact behavior of the tibiofemoral joint. Osteoarthritis Cartilage. 2010;18(7):909-16

23. Englund $\mathrm{M}$. The role of biomechanics in the initiation and progression of $\mathrm{OA}$ of the knee. Best Pract Res Clin Rheumatol. 2010;24(1):39-46.

24. Pearle AD, Warren RF, Rodeo SA. Basic science of articular cartilage and osteoarthritis. Clin Sports Med. 2005;24(1):1-12.

25. Silver FH, Bradica G, Tria A. Relationship among biomechanical, biochemical, and cellular changes associated with osteoarthritis. Crit Rev Biomed Eng. 2001;29(4):373-91.

26. Slavens BA, Harris GF. The biomechanics of upper extremity kinematic and kinetic modeling: applications to rehabilitation engineering. Crit Rev Biomed Eng. 2008;36(2-3): 93-125.

27. Bhagchandani N, Slavens B, Wang M, Harris G. Upper extremity biomechanical model of crutchassisted gait in children. Conf Proc IEEE Eng Med Biol Soc. 2009;2009:7164-7.

28. Faruqui SR, Jaeblon T. Ambulatory assistive devices in orthopaedics: uses and modifications. J Am Acad Orthop Surg. 2010;18(1):41-50. 